\title{
A Flexible Monopole Antenna with Dual-Notched Band Function for Ultrawideband Applications
}

\author{
Xiaoyan Zhang ${ }^{1,2}$ and Guohao Wang ${ }^{1}$ \\ ${ }^{1}$ School of Information Engineering, East China Jiaotong University, Nanchang 330013, China \\ ${ }^{2}$ The State Key Laboratory of Millimeter Wave, Nanjing 210018, China \\ Correspondence should be addressed to Guohao Wang; wguoh178@163.com
}

Received 24 April 2014; Accepted 10 November 2014; Published 20 November 2014

Academic Editor: Michael Y. W. Chia

Copyright (c) $2014 \mathrm{X}$. Zhang and G. Wang. This is an open access article distributed under the Creative Commons Attribution License, which permits unrestricted use, distribution, and reproduction in any medium, provided the original work is properly cited.

\begin{abstract}
We present a flexible ultrawideband (UWB) planar monopole antenna with dual-notched band characteristic printed on a polyimide substrate. The antenna is fed by a step coplanar waveguide (CPW) that provides smooth transitional impedance for improved matching. It operates from 2.76 to $10.6 \mathrm{GHz}$ with return loss greater than $10 \mathrm{~dB}$ except for the notch band to reduce the interference with existing $3.5 \mathrm{GHz}$ WiMAX band and $5.5 \mathrm{GHz}$ WLAN band. With a combination of rectangular and circle patches in which the U-shaped slot is carved, the overall size of antenna is $30 \mathrm{~mm} \times 20 \mathrm{~mm}$. Moreover, a pair of arc-shaped stubs located at both sides of the feed line is utilized to create the notch band for WiMAX band. The results also show that the antenna has omnidirectional radiation pattern and smooth gain over the entire operational band.
\end{abstract}

\section{Introduction}

With the rapid advance in wireless communication techniques, UWB system has become one of the most fascinating technologies for indoor communications. For its merits of high speed transmission rate, low power consumption, and simple hardware configuration, UWB system can be used in various applications and devices such as a wireless USB dongle or small terminal for UWB system. Recently, many laboratories and firms have developed UWB antennas [1-3], but most antennas are solid planer types and they cannot be mounted on a small terminal. So, the flexible UWB antennas applicable to the various kinds of the small devices are needed.

Yoon et al. presented a flexible UWB antenna which is fabricated on PET film and analyzed the characteristics of the flexible antenna when it is mounted on various kinds of conformal materials with the various dielectric constants [4]. It used a rectangle as a radiation patch to reduce the deterioration of the bow because the current will not be changed largely in bending. And then, Khaleel et al. presented a compact UWB antenna printed on a polyimide substrate [5]. The proposed design is tuned to cover the $2.2-14.3 \mathrm{GHz}$ frequency and $\mathrm{CPW}$ feeding with tapering structure is the key to impedance matching. Although flexible and UWB characteristic has been achieved, proposed antennas cannot carry a notched band performance except by using a filter [6]. A compact filter-combined UWB antenna has been carried in [6]. With a rectangular filter and an UWB antenna, the overall size of the proposed structure has reached $49 \times 30 \mathrm{~mm}$ which will limit its application. What is more, the flexible substrate will influence the filter. Peter and Nilavalan proposed an UWB antenna has a notched band feature and make a study on the performance deterioration of flexible UWB antennas in [7]. It used a pair of slots that are placed symmetrically on both sides of the patch to create the band notch characteristic that covers $4 \mathrm{GHz}$ to $5.5 \mathrm{GHz}$. By the measured result we can see the proposed antenna does not have a good performance on high-frequency part. Bae et al. improve their design in [8]. An antenna with notch-band characteristic of $5 \mathrm{GHz}$ WLAN band is presented. From the $S$-parameter, the proposed antenna shows good result on return loss, but the antenna does not avoid the $3.5 \mathrm{GHz}$ WiMax band.

In this work, we present a flexible UWB antenna with dual-notched band $3.5 \mathrm{GHz}$ WiMax and $5.5 \mathrm{GHz}$ WLAN. The paper is organized as follows. In Section 2, an antenna 


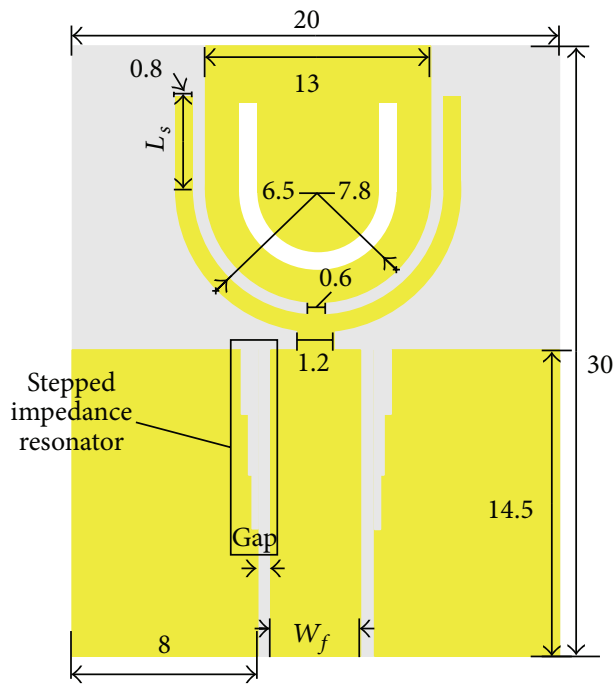

Figure 1: Structure of the proposed band-notched antenna (unit: $\mathrm{mm}$ ).

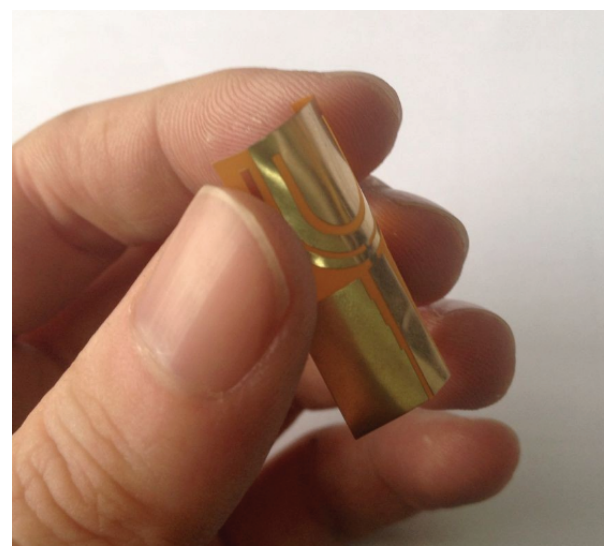

Figure 2: The fabricated photograph of the proposed antenna.

element is studied first, and parameters of the antenna element are discussed; in Section 3, simulated and measured results are presented; furthermore, a comparison between stepped ground and rectangular ground structure is also given in this section.

\section{Antenna Element Design}

Figure 1 shows the layout of the proposed UWB planar monopole antenna. It consists of four parts: a radiating patch, a rectangular microstrip feeding line, two small rectangular ground planes with step-shaped structure, andarc-shaped stubs located at both sides of the transition. The geometric design of the radiating patch consists of a circle, a rectangle, and a rectangular transition. To make the antenna have a flexible characteristic, polyimide is selected as a substrate for its soft and easy bending. The overall size of the proposed antenna is $30 \mathrm{~mm} \times 20 \mathrm{~mm}$, and it is designed on a polyimide with a thickness of $h=0.2 \mathrm{~mm}$ (Figure 2); the relative dielectric constant of the substrate is 3.5 with a loss tangent of 0.003 .
The width of the feeding line $(W)$ is decided by the formula [9]:

$$
\begin{gathered}
Z_{0}=\frac{120 \pi}{\sqrt{\varepsilon_{\mathrm{eff}}\{w / h+1.393+0.677 \times \ln (w / h+1.444)\}}}, \\
\varepsilon_{\mathrm{eff}}=\frac{\varepsilon_{r}+1}{2}+\frac{\varepsilon_{r}-1}{2}\left(1+12 \frac{h}{w}\right)^{-1 / 2} .
\end{gathered}
$$

When the $\varepsilon_{r}=3.5, h=0.2 \mathrm{~mm}$, and $Z_{0}=50 \mathrm{ohm}$, $W_{f}$ is about $3.16 \mathrm{~mm}$. Considering the influence of the SMA connector in practical, we set $W_{f}=3.2 \mathrm{~mm}$. Arc-shaped stubs which produce the $3.5 \mathrm{GHz}$ notched band work in $0.25 \lambda_{e}\left(\lambda_{e}=\lambda \sqrt{\varepsilon_{\mathrm{eff}}}\right)$ mode, and the length is defined by

$$
L=\frac{\lambda}{4}=\frac{c}{4 f} .
$$

By calculating the $\lambda$ in free space and on the substrate, respectively, we can know $0.25 \lambda_{e}<L<0.25 \lambda$. $L_{S}$ is optimized by CST Microwave Studio, which we can see from Figure 3. The resonant frequency will be various when $L$ is 


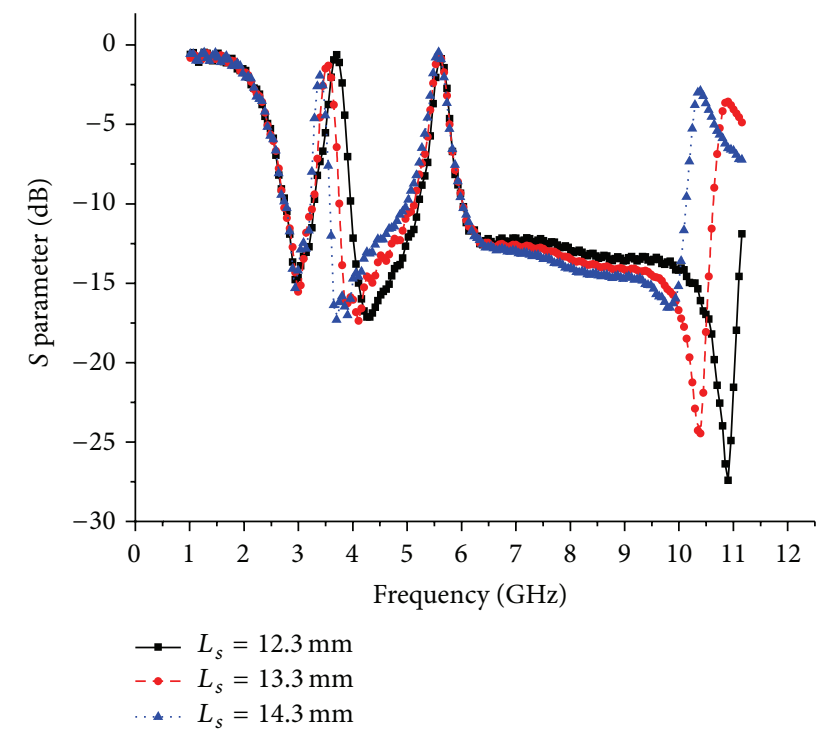

Figure 3: The length of $L_{s}$ optimized by CST.

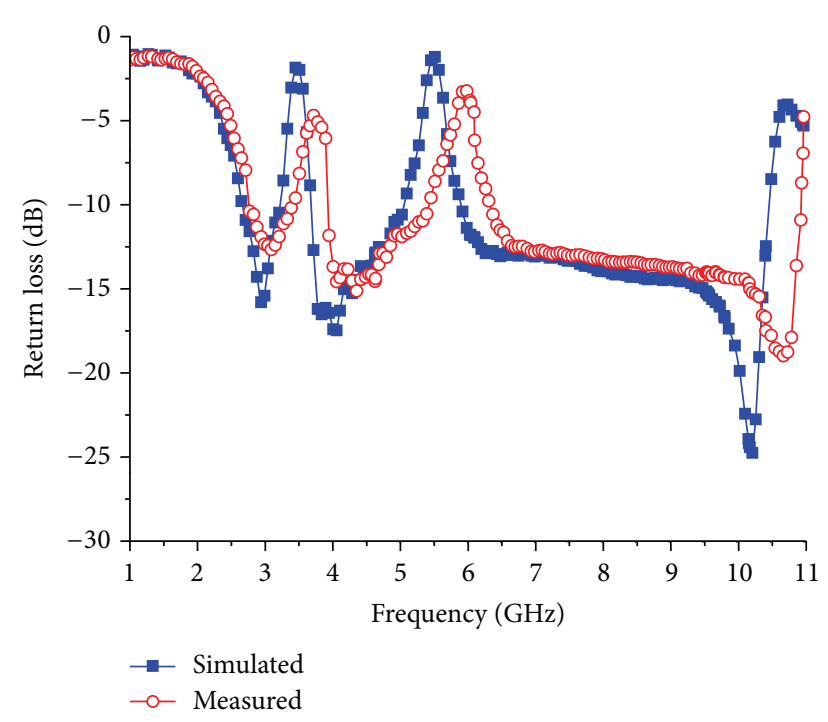

FIGURE 4: Simulated and measured performance of the antenna.

changed. What is more, the second notched band is almost not affected by the length of $L$ which reveals these two notched bands have good isolation. The same method is also used to define the length of the slot. The U-shaped slot structure located in the radiation patch produces a notched band for $5.5 \mathrm{GHz}$ WLAN band, and the resonant frequency is defined by the length of the slot.

\section{Result and Discussion}

The return loss of the proposed antenna can be seen in Figure 4. As shown, the proposed antenna operates from 2.76 to $10.6 \mathrm{GHz}$ with return loss $>10 \mathrm{~dB}$ except for the 3.5 GHz WiMax and $5.5 \mathrm{GHz}$ WLAN bands. Compared to the simulated result, the measured one has a frequency

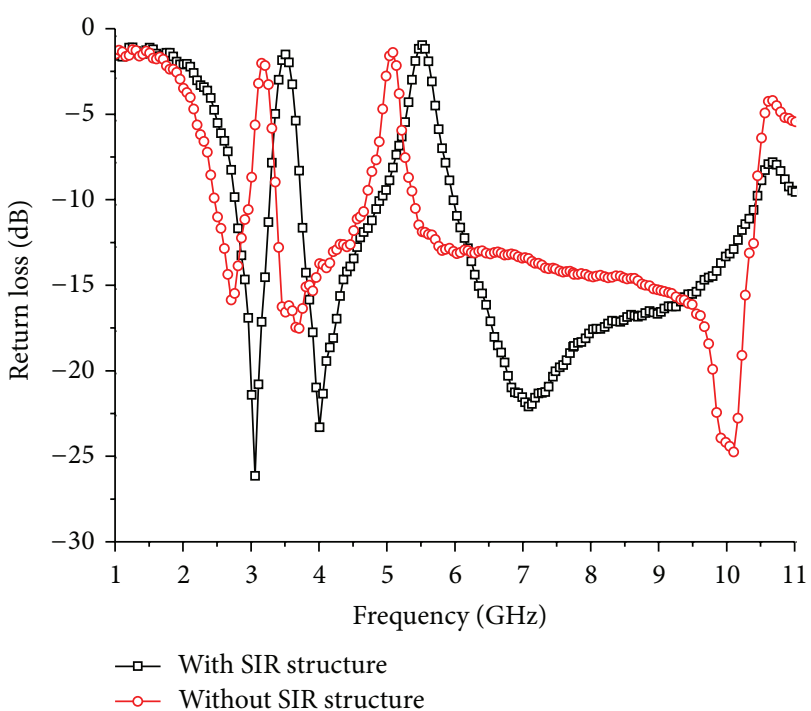

Figure 5: Comparison for different structures of the ground.

deviation for the proposed antenna has a little deformation when welding the SMA connector. Despite the deviation, the measured curve is close to the simulated one and it can operate from $3.1 \mathrm{GHz}$ to $10.6 \mathrm{GHz}$.

Function of stepped slots on the ground near the feeding line will be discussed in this part. Stepped impedance resonator (SIR) is usually designed to control the higher harmonics [10]. And in the proposed antenna, SIR is also used to form a stop-band at 10.6 GHz. As we can see from Figure 5, without the SIR structure, the S11 curve is about $-10 \mathrm{~dB}$ at $10.6 \mathrm{GHz}$ while the one with the SIR is about only $-3 \mathrm{~dB}$. The SIR structure pulls the higher harmonics of $3.5 \mathrm{GHz}$ notched band closer to $10.6 \mathrm{GHz}$ which form a stop-band to isolate other signals.

Figure 6 shows the far-field radiation patterns of the proposed antenna at the frequency of $2.76,5.5$, and $10.6 \mathrm{GHz}$ in the principal planes and the maximum direction at each frequency is $1.92,3.55$, and 5.43 . As can be seen, the antenna exhibits an omnidirectional radiation in the $H$-plane. The $E$ plane radiation patterns of antennas are similar to those of a dipole at the same electric lengths.

\section{Conclusion}

In this paper, a flexible monopole antenna with dual-notched band function for ultrawideband applications has been proposed and presented. The proposed antenna is fabricated on a polyimide substrate and the flexible character makes the antenna wider application, which serves as the design guidance for other researchers. The effects of the dimensions of the U-shaped stubs on the band-notch characteristics of the proposed antenna are also analyzed by the theory of $0.25 \lambda_{e}$ mode. The results on return loss and radiation patterns show that the proposed antenna fully satisfies the bandwidth requirement of UWB applications with omnidirectional radiation patterns and sharp band-notched performance. 

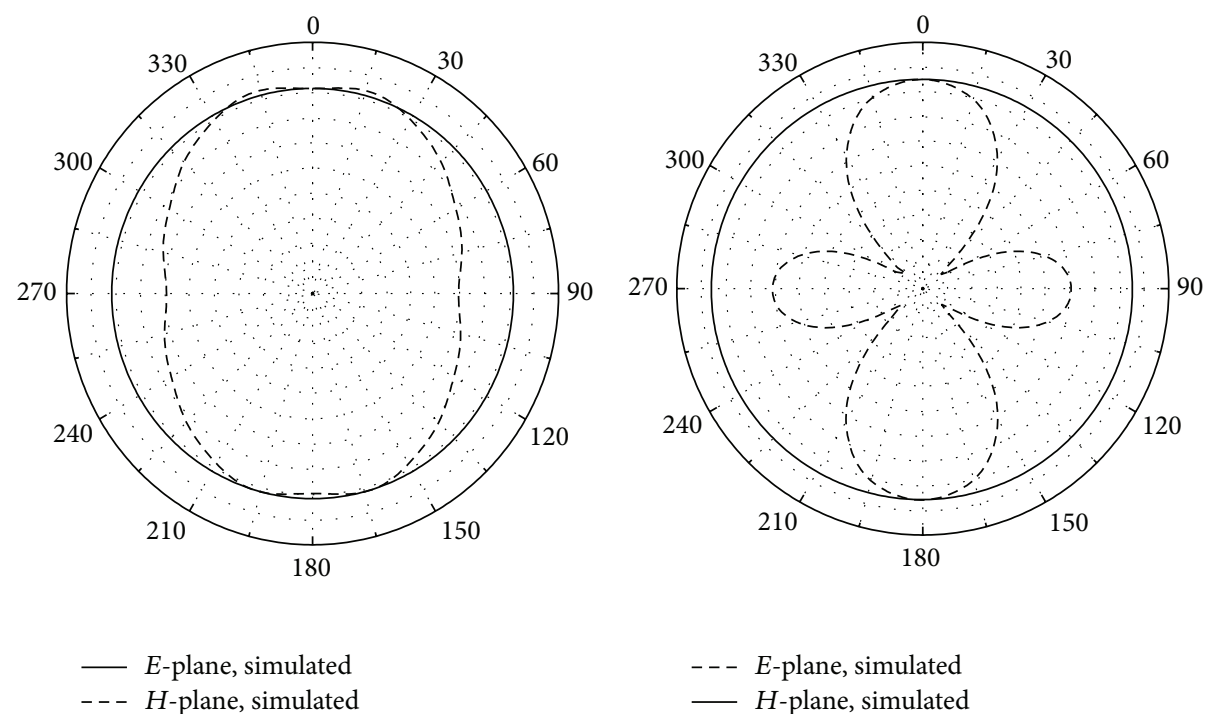

- E-plane, simulated

- H-plane, simulated

(a) $2.76 \mathrm{GHz}$

(b) $5.5 \mathrm{GHz}$



(c) $10.6 \mathrm{GHz}$

FIGURE 6: The simulated radiation patterns at $2.76 \mathrm{GHz}, 5.5 \mathrm{GHz}$, and $10.6 \mathrm{GHz}$.

\section{Conflict of Interests}

The authors declare that there is no conflict of interests regarding the publication of this paper.

\section{Acknowledgments}

This work was supported in part by the National Natural Science Foundation of China (nos. 61061002 and 61261005), the Graduate Special Fund Innovative Projects in Jiangxi Province (no. YC2013-S158), Jiangxi Provincial Department of Education Project which is funded (no. GJJ13352), and the Open Project of State Key Laboratory of Millimeter Wave (no. K201325).

\section{References}

[1] M. Koohestani and M. Golpour, "Very ultra-wideband printed CPW-fed slot antenna," Electronics Letters, vol. 45, no. 21, pp. 1066-1067, 2009.

[2] X. Chen, W. Zhang, R. Ma, J. Zhang, and J. Gao, "Ultrawideband CPW-fed antenna with round corner rectangular slot and partial circular patch," IET Microwaves, Antennas and Propagation, vol. 1, no. 4, pp. 847-851, 2007.

[3] M.-J. Chiang, T.-F. Hung, J.-Y. Sze, and S.-S. Bor, "Miniaturized dual-band CPW-Fed annular slot antenna design with arc-shaped tuning stub," IEEE Transactions on Antennas and Propagation, vol. 58, no. 11, pp. 3710-3715, 2010.

[4] H. K. Yoon, W. S. Kang, Y. J. Yoon, and C.-H. Lee, "A flexible UWB antenna attachable to various kinds of materials," in 
Proceedings of the IEEE International Conference on Source, 2007.

[5] H. R. Khaleel, H. M. Al-Rizzo, D. G. Rucker, and S. Mohan, "A compact polyimide-based UWB antenna for flexible electronics," IEEE Antennas and Wireless Propagation Letters, vol. 11, pp. 564-567, 2012.

[6] A. Khidre, A. Abdel Rahman, H. Elsadek, A. Omar, and H. Ragai, "UWB printed monopole antenna with embedded reconfigurable multiband filter based on miniaturized ground plane slot," Microwave and Optical Technology Letters, vol. 52, no. 9, pp. 2076-2080, 2010.

[7] T. Peter and R. Nilavalan, "Study on the performance deterioration of flexible UWB antennas," in Proceedings of the Loughborough Antennas \& Propagation Conference, November 2009.

[8] S. W. Bae, H. K. Yoon, W. S. Kang, Y. J. Yoon, and C.-H. Lee, "A flexible monopole antenna with band-notch function for UWB systems," in Proceedings of the Asia-Pacific Microwave Conference (APMC '07), December 2007.

[9] R. N. Simons, Coplanar Waveguide Circuits, Components, and Systems, John Wiley \& Sons, New York, NY, USA, 2001.

[10] H.-W. Deng, Y.-J. Zhao, L. Zhang, X.-S. Zhang, and S.-P. Gao, "Compact quintuple-mode stub-loaded resonator and UWB filter," IEEE Microwave and Wireless Components Letters, vol. 20, no. 8, pp. 438-440, 2010. 

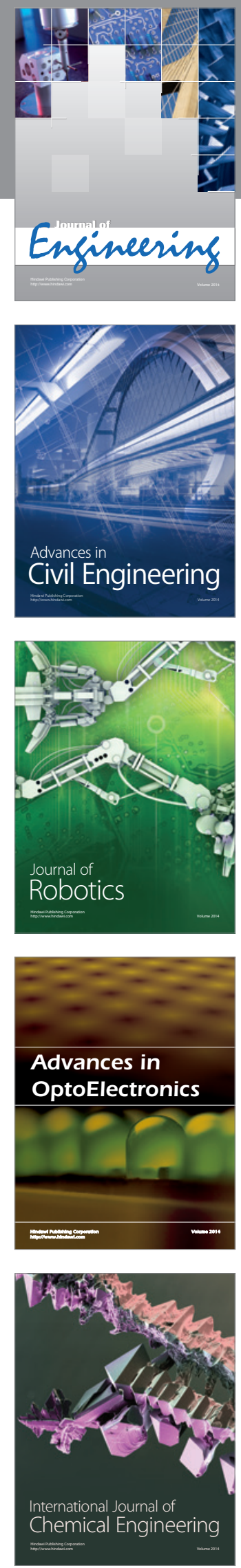

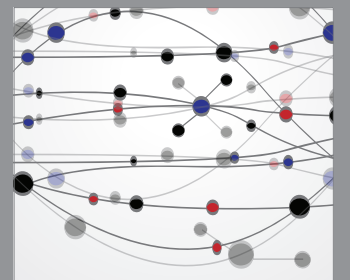

The Scientific World Journal
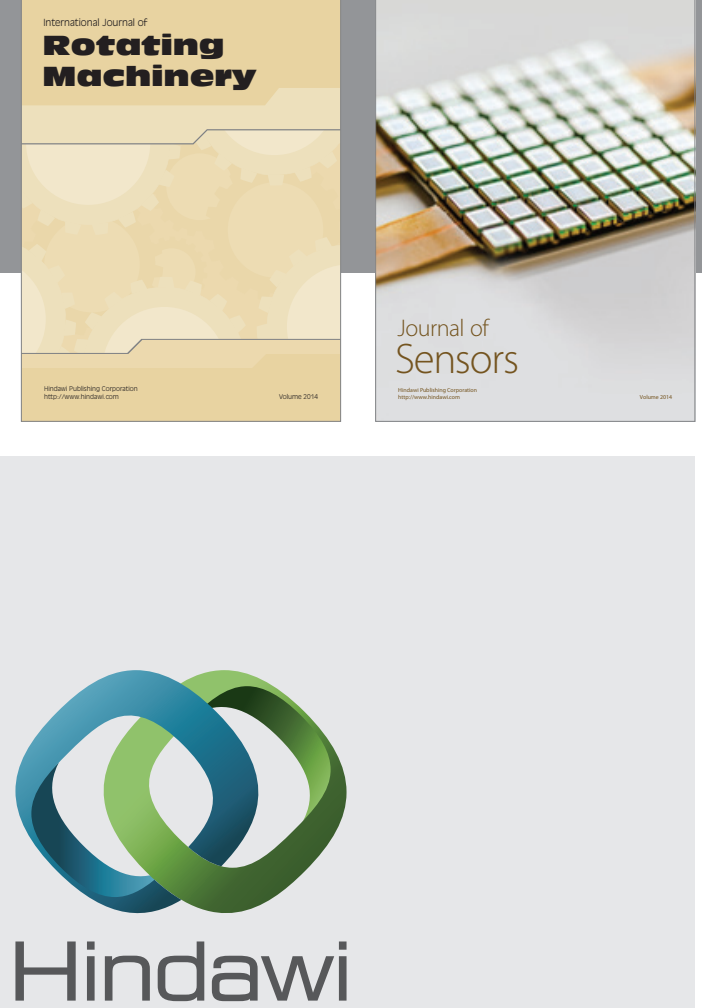

Submit your manuscripts at http://www.hindawi.com
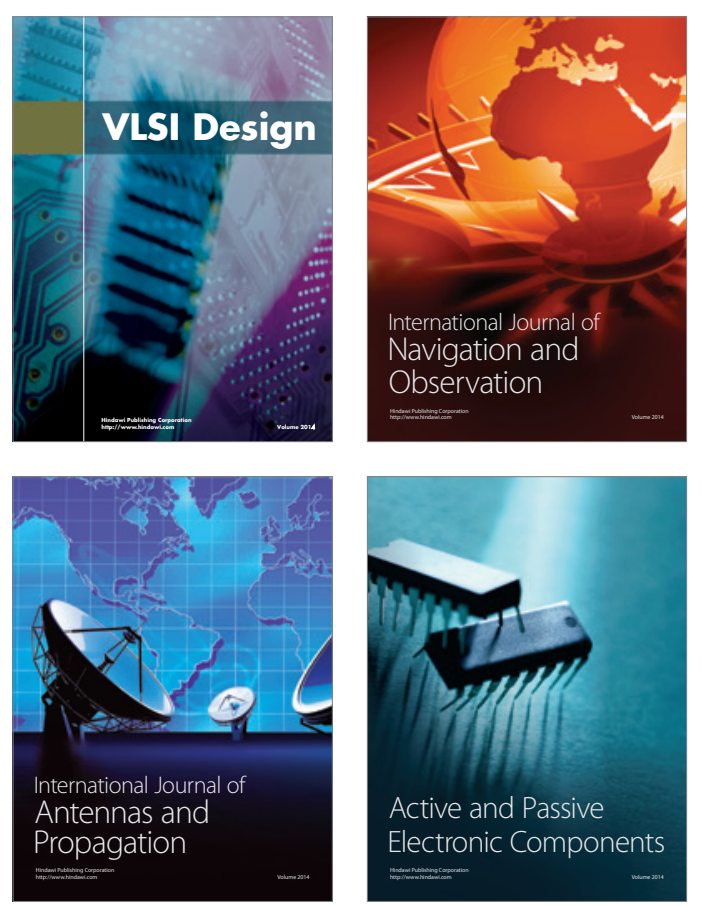
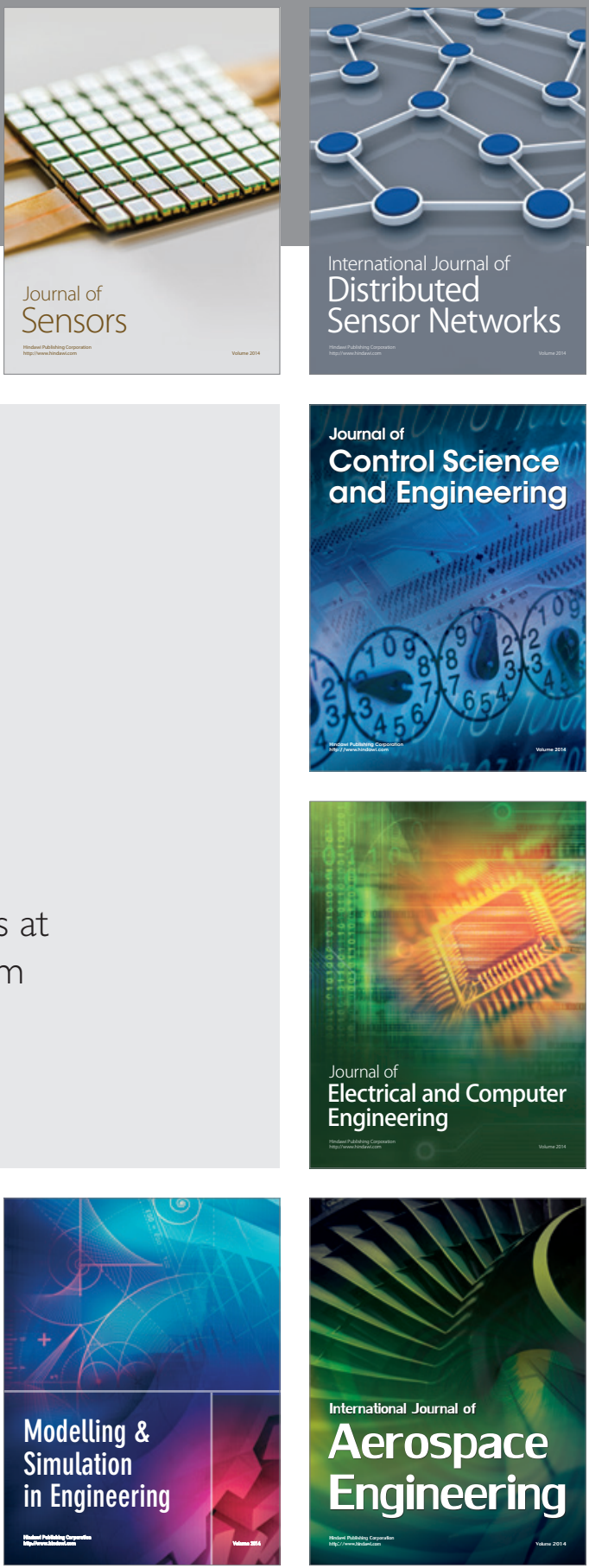

Journal of

Control Science

and Engineering
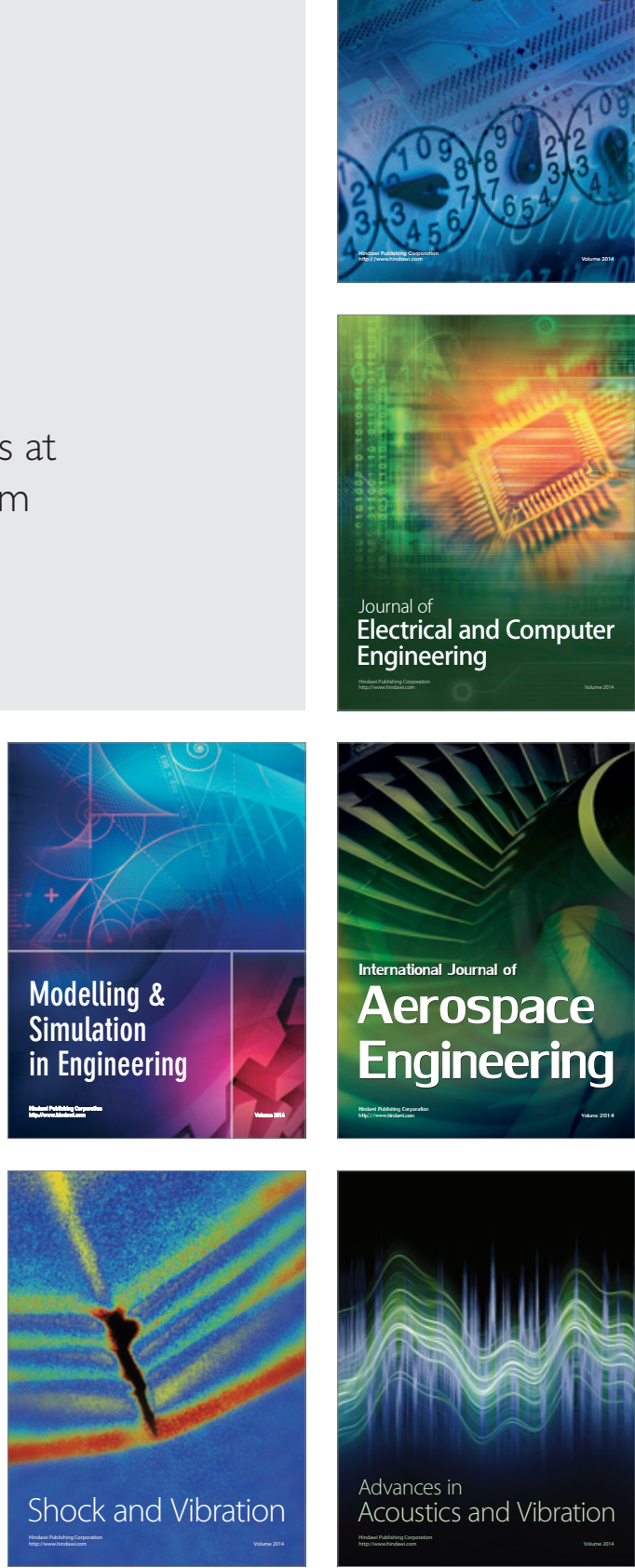